\title{
MATHEMATICAL MODELING OF LACTOBACILLUS VIRIDESCENS AND LACTOBACILLUS SAKEI GROWTH AT SIX DIFFERENT TEMPERATURES
}

\author{
F. DALCANTON ${ }^{1}$, F. R. S. MACHADO JR ${ }^{2}$, D. A. LONGHI ${ }^{3}$, B. A. M. CARCIOFI ${ }^{3}$, J. B. \\ LAURINDO $^{3}$ e G. M. F. ARAGÃO ${ }^{3}$ \\ ${ }^{1}$ Universidade Comunitária da Região de Chapecó, Área de Ciências Exatas e Ambientais \\ ${ }^{2}$ Universidade Federal do Rio Grande, Escola de Química e Alimentos \\ ${ }^{3}$ Universidade Federal de Santa Catarina, Departamento de Engenharia de Alimentos \\ E-mail para contato: fdalcanton@unochapeco.edu.br
}

\begin{abstract}
Lactic acid bacteria are the main microorganisms group responsible for the spoilage of refrigerated vacuum-packaged meat products, such as ham, sausage, chicken breast, among others. The main of this study was to model the growth of Lactobacillus viridescens and Lactobacillus sakei in culture medium at different temperatures. In this study, four primary growth models (Gompertz, Logistic, modified Logistic, and Baranyi-Roberts) were compared using the indices $\mathrm{R}^{2}$, MSE, bias, and accuracy factor. The Gompertz model presented the best fit and was used for obtaining the growth parameters (lag phase duration $(\lambda)$, maximum specific growth rate $(\mu)$, and microbial population increase (A)) for L. viridescens and L. sakei at six growth temperatures $\left(4,8,12,16,20\right.$ and $\left.30^{\circ} \mathrm{C}\right)$. From this study it can be seen that the growth of lactic acid bacteria is strongly influenced by the temperature of storage even under refrigerated conditions.
\end{abstract}

\section{INTRODUCTION}

Lactic acid bacteria group (LAB) was identified as the main spoilage population of vacuum-packaged and modified atmosphere meat products, and other processed products stored under refrigeration temperatures. The most frequent strains of LAB in meats and meat products are: Lactobacillus sakei, Lactobacillus viridescens, Lactobacillus plantarum, Lactobacillus curvatus, Leuconostoc mesenteroides, Carnobacterium piscicola, Carnobacterium divergens (Hugas, 1998). The spoilage caused by LAB is primarily due to the production of metabolites, which cause undesirable alterations in appearance, texture and flavor, producing unpleasant odors and flavors, along with the discoloring and slime production on the product's surface (Samelis et al., 2000).

Temperature seems to be the most important factor that influences food spoilage as well as safety. Hence, cold chain control is very important to avoid rapid and uncontrollable microbial growth, which reduce product shelf-life and may endanger public health (Nychas et al., 2008).

The continuous progress of science and technology of food preservation involves the development of new food microbiology tools. The need of assuring microbiological safety 
and high quality foods has been stimulating the application of predictive microbiology tools. Predictive microbiology basically focuses on the development of mathematical models to describe the growth of pathogens and spoilage microorganisms in food, helping predicting food shelf-life (Nakashima et al., 2000; Brul et al., 2008).

The so-called primary growth models are those that describe the behavior of microorganisms during storage time (Whiting, 1995). They use three parameters in the characterization of bacterial growth curve, i.e., the lag phase duration $(\lambda)$, the maximum specific growth rate $(\mu)$, and the microbial population increase (A). Primary models such as Gompertz, Logistic, modified Logistic, and Baranyi-Roberts models are often used for fitting microbial growth data (Buchanan et al., 1997; Erkmen and Alben, 2002; Corradini and Peleg, 2005; Pal et al., 2008).

The main of this study was to independently research $L$. sakei and L. viridescens growth at different temperatures $\left(4,8,12,16,20\right.$ and $\left.30^{\circ} \mathrm{C}\right)$, comparing the ability of the aforementioned primary models (Gompertz, Logistic, modified Logistic, and BaranyiRoberts) to describe the growth curves.

\section{MATERIAL AND METHODS}

Lactobacillus sakei (ATCC 15521) and Lactobacillus viridescens (ATCC 12706) were grown in MRS (Man, Rogosa and Sharpe) - Lactobacillus broth (Acumedia).

\subsection{Growth Conditions}

The inoculums were grown for $18 \mathrm{~h}$ in MRS broth at $30^{\circ} \mathrm{C}$. After this period, the inoculums were used to determine microbial growth curves at different temperatures: 4 and $8^{\circ} \mathrm{C}$ (refrigeration temperature), 12,16 and $20^{\circ} \mathrm{C}$ (temperature abuse) and $30^{\circ} \mathrm{C}$ (optimum bacterial growth temperature). Experiments were carried out in $160 \mathrm{~mL}$ of MRS broth with $1 \%(\mathrm{v} / \mathrm{v})$ of inoculum in $250 \mathrm{~mL}$ Erlenmeyer flasks. The initial $\mathrm{pH}$ was adjusted at 6 . The flasks were maintained in an incubator (Dist) and the microbial growth evolution was determined until the stationary stage. For each LAB, at each tested temperature, four growth curves were generated: two duplicates at two different days (independent trials). The exception was the $L$. sakei, for which two curves were generated at $16^{\circ} \mathrm{C}, 20^{\circ} \mathrm{C}$ and $30^{\circ} \mathrm{C}$.

Samples of $2 \mathrm{~mL}$ were collected aseptically in a laminar flow device (CFLV-09, Vecol) at predetermined intervals, depending on the temperature of growth. LAB growth was determined by absorbance (abs) at $600 \mathrm{~nm}$ wavelength in a spectrophotometer $(1105$, Bel Photonics). The $\mathrm{pH}$ was measured by a pHmeter (V620, Analion). The growth curves were followed until the stationary phase was achieved, and were obtained by plotting $\ln \left(\mathrm{abs}_{\mathrm{abs}}\right)$ versus time. The term abs represents the absorbance at time $t$ and $\mathrm{abs}_{0}$ the initial absorbance. 


\subsection{Modeling L. sakei and L. viridescens Growth at Various Temperatures}

The primary models (Gompertz, Logistic, modified Logistic, and Baranyi-Roberts) were fit to $\mathrm{LAB}$ growth curves. Table 1 shows the equations representing each primary model. The growth curves were fitted using Matlab 7 software (MathWorks ${ }^{\mathrm{TM}}$, Natick, MA, USA) with Gompertz, Logistic and modified Logistic models, and DMfit program - Baranyi and Roberts (1994) - (Excel add-in) to Baranyi-Roberts model.

Table 1. Primary growth models used to fit the growth of LAB

\begin{tabular}{ll}
\hline Primary models & Equations $^{\mathbf{a}}$ \\
\hline Gompertz & $\ln \left(a b s / \mathrm{abs}_{0}\right)=A \cdot \exp \{-\exp [-B \cdot(t-M)]\}$ \\
& $\mu=\frac{A \cdot B}{e} \quad \lambda=M-\frac{1}{B}$
\end{tabular}

Logistic

$$
\begin{aligned}
& \ln \left(a b s / \mathrm{abs}_{0}\right)=\frac{A}{[1+\exp [-B \cdot(t-M)]} \\
& \mu=\frac{A \cdot B}{4} \quad \lambda=\frac{(M-2)}{B}
\end{aligned}
$$

Modified Logistic

$$
\begin{aligned}
& \ln \left(a b s / a b s_{0}\right)=\frac{A}{(1+\exp [-B \cdot(t-M)}-\frac{A}{(1+\exp (M \cdot B))} \\
& \mu=\frac{A \cdot B}{4} \quad \lambda=\frac{(M-2)}{B}
\end{aligned}
$$

Baranyi-Roberts

$$
\begin{aligned}
& a b s=a b s_{0}+\mu \cdot F(t)-\frac{1}{m} \ln \left(1+\frac{\exp (m \cdot \mu \cdot F(t))-1}{\exp \left(m\left(a b s_{\max }-a b s_{0}\right)\right)}\right) \\
& F(t)=t+\frac{1}{\mu} \ln (\exp (-\mu \cdot t)+\exp (-\mu \cdot \lambda)-\exp (-\mu(t+\lambda)))
\end{aligned}
$$

\footnotetext{
${ }^{\mathrm{a}} \ln \left(\mathrm{abs} / \mathrm{abs}_{0}\right)$ : is the logarithm of the cell density at time $t$; abs: absorbance at time $t$; $\operatorname{abs}_{0}$ : initial absorbance; $\mathrm{A}$ is the logarithmic microbial population increase; $\mu$ : maximum specific growth rate $\left(\mathrm{h}^{-1}\right) ; \lambda$ : lag phase duration (h); B is the relative growth rate at time $\mathrm{M}\left(\mathrm{h}^{-1}\right)$, and $\mathrm{M}$ is the time required to reach the maximum rate growth $(\mathrm{h})$; $\mathrm{abs}_{\max }$ : maximum absorbance, $\mathrm{m}$ is the curvature parameter; $\mathrm{e}=2.7182$.
}

Mathematical models comparisons were performed using the statistical indices: correlation coefficient $\left(\mathrm{R}^{2}\right)$, mean square error (MSE), bias factor, and factor accuracy (Sutherland et al., 1994; Ross, 1996). These statistical indices are shown in Table 2. 
Table 2. Statistical indices for comparison of the models

\begin{tabular}{ll}
\hline Statistical indices & Equation $^{\text {a }}$ \\
\hline MSE & MSE $=\frac{\sum\left(\text { Value }_{\text {observed }}-\text { Value }_{\text {predicted }}\right)^{2}}{\mathrm{n}-\mathrm{p}}$ \\
Bias factor & bias factor $=10^{\left(\sum \frac{\log \left(\text { Value }_{\text {prediced }} / \text { Value }_{\text {observed }}\right)}{\mathrm{n}}\right)}$ \\
Accuracy factor & accuracyfactor $\left.=10^{\left(\sum \frac{\log \left(\text { Value }_{\text {predicted }} / \text { Value }_{\text {oberved }}\right)}{\mathrm{n}}\right)}\right)$ \\
\hline
\end{tabular}

${ }^{\mathrm{a}} \mathrm{n}$ : number of experimental data; $\mathrm{p}$ : number of model parameters.

\section{RESULTS AND DISCUSSION}

Table 3 show the range of statistical indices values obtained for primary models for the six growth temperatures for $L$. viridescens. The range represents the lowest and the highest indices values obtained by fitting the models to the four replicate growth curves, at each investigated temperature. The calculated statistical indices showed that all models represented well the growth behavior of these LAB. However, visual analysis of these fittings (data not presented) showed that the Logistic and Baranyi-Roberts models did not describe well the lag phase of growth curves for various investigated situations. The same behavior was observed for L. sakei.

As it can also be observed in Table 3, statistical indices of the Logistic and BaranyiRoberts models are slightly lower than the values observed for Gompertz and modified Logistic models, with a slightly superior performance for the Gompertz model, which was the only one that showed correlation coefficients above 0.99 , for all temperatures. The lowest values of the mean square error were observed for the Gompertz model. Bias and accuracy factors closer to 1 were also obtained for the Gompertz model.

Through analysis of the statistical indices, the primary model that showed the best fit to growth curves of $L$. viridescens and $L$. sakei, at all investigated temperatures, was the Gompertz model. Therefore, this model was chosen for the calculation of the growth parameters of LAB. These results match those reported by Slongo et al. (2009) who studied the influence of pressure level and holding time during high pressure treatment of ham on LAB growth in vacuum-packaged sliced ham. These authors reported that both modified Gompertz and Logistic models were able to describe microbial growth in ham. However, Gompertz model had a slightly superior performance. Zwietering et al. (1990) compared several sigmoidal functions (Logistic, Gompertz, Richards, Schnute, and Stannard models) for describing $L$. plantarum growth curves in MRS broth at different temperatures $\left(6^{\circ} \mathrm{C}\right.$ to 
$42.8^{\circ} \mathrm{C}$ ). These authors concluded that all growth curves were better fitted with the Gompertz model.

Table 3. Range of statistical indices values for Gompertz, Logistic, modified Logistic, and Baranyi-Roberts models, obtained by fitting the growth curves of L. viridescens

\begin{tabular}{|c|c|c|c|c|}
\hline \multirow{2}{*}{$\begin{array}{l}\text { Temperature/ } \\
\text { Indices }\end{array}$} & \multicolumn{4}{|c|}{ Models } \\
\hline & Gompertz & Logistic & Modified Logistic & Baranyi \\
\hline \multicolumn{5}{|l|}{$30^{\circ} \mathrm{C}$} \\
\hline $\mathrm{R}^{2}$ & 0.998-0.999 & 0.995-0.999 & 0.996-0.999 & $0.992-0.998$ \\
\hline MSE & $0.003-0.004$ & $0.002-0.009$ & $0.001-0.007$ & $0.004-0.012$ \\
\hline Bias & $1.002-1.015$ & $0.985-0.993$ & $0.990-0.998$ & $0.945-1.033$ \\
\hline Accuracy & $1.039-1.047$ & $1.034-1.045$ & $1.026-1.065$ & $1.063-1.100$ \\
\hline \multicolumn{5}{|l|}{$20^{\circ} \mathrm{C}$} \\
\hline $\mathrm{R}^{2}$ & 0.998-0.999 & 0.994-0.999 & 0.996-0.999 & 0.989-0.997 \\
\hline MSE & $0.002-0.004$ & $0.003-0.015$ & $0.002-0.011$ & $0.004-0.023$ \\
\hline Bias & 0.999-1.012 & $0.981-0.992$ & 0.988-0.998 & 0.949-1.041 \\
\hline Accuracy & $1.039-1.052$ & $1.042-1.113$ & 1.036-1.088 & $1.075-1.098$ \\
\hline \multicolumn{5}{|l|}{$16^{\circ} \mathrm{C}$} \\
\hline $\mathrm{R}^{2}$ & 0.994-0.998 & 0.997-0.999 & 0.997-0.999 & 0.994-0.997 \\
\hline MSE & $0.003-0.010$ & $0.001-0.005$ & 0.001-0.005 & 0.003-0.007 \\
\hline Bias & 0.997-1.027 & $0.982-1.005$ & $0.985-1.013$ & $0.966-1.003$ \\
\hline Accuracy & $1.042-1.075$ & $1.030-1.051$ & $1.022-1.055$ & $1.033-1.091$ \\
\hline \multicolumn{5}{|l|}{$12^{\circ} \mathrm{C}$} \\
\hline $\mathrm{R}^{2}$ & 0.994-0.999 & $0.986-0.997$ & 0.989-0.998 & $0.976-0.996$ \\
\hline MSE & $0.001-0.010$ & $0.003-0.022$ & $0.002-0.016$ & 0.005-0.029 \\
\hline Bias & 0.993-1.004 & $0.981-0.988$ & 0.987-0.994 & 0.985-1.037 \\
\hline Accuracy & $1.022-1.076$ & $1.049-1.127$ & $1.036-1.095$ & $1.081-1.228$ \\
\hline \multicolumn{5}{|l|}{$8^{\circ} \mathrm{C}$} \\
\hline $\mathrm{R}^{2}$ & 0.998-0.999 & 0.994-0.998 & 0.996-0.998 & 0.991-0.996 \\
\hline MSE & $0.001-0.002$ & $0.003-0.006$ & $0.002-0.004$ & 0.004-0.008 \\
\hline Bias & 0.999-1.005 & $0.986-0.992$ & 0.991-0.997 & $1.004-1.066$ \\
\hline Accuracy & $1.024-1.035$ & $1.041-1.062$ & $1.032-1.052$ & $1.033-1.111$ \\
\hline \multicolumn{5}{|l|}{$4^{\circ} \mathrm{C}$} \\
\hline $\mathrm{R}^{2}$ & 0.995-0.997 & 0.992-0.998 & 0.996-0.998 & $0.990-0.998$ \\
\hline MSE & $0.001-0.002$ & $0.001-0.003$ & $0.001-0.003$ & $0.001-0.003$ \\
\hline Bias & $1.000-1.007$ & 0.992-0.997 & 0.997-1.003 & $0.964-1.010$ \\
\hline Accuracy & $1.029-1.045$ & $1.023-1.044$ & $1.018-1.044$ & $1.077-1.160$ \\
\hline
\end{tabular}

Figures 1 and 2 shows the growth curves of L. viridescens and L. sakei, respectively, at six different temperatures, fitted by the Gompertz model. Each temperature is exemplified by only one curve in each cultivation condition. It can be observed that the model describes well all the growth curves. Analyzing these figures, it is possible to verify the behavior of the two LAB in each storage condition, and that the temperature decrease causes the increase of the lag phase, and the decrease of the maximum specific growth rate and of the maximum population. The two strains had a very similar behavior. They just showed little difference on 
the curves at $20^{\circ} \mathrm{C}$ and $16^{\circ} \mathrm{C}$ of $L$. viridescens, for which the growth curves were very similar, a behavior not observed for the other strain.

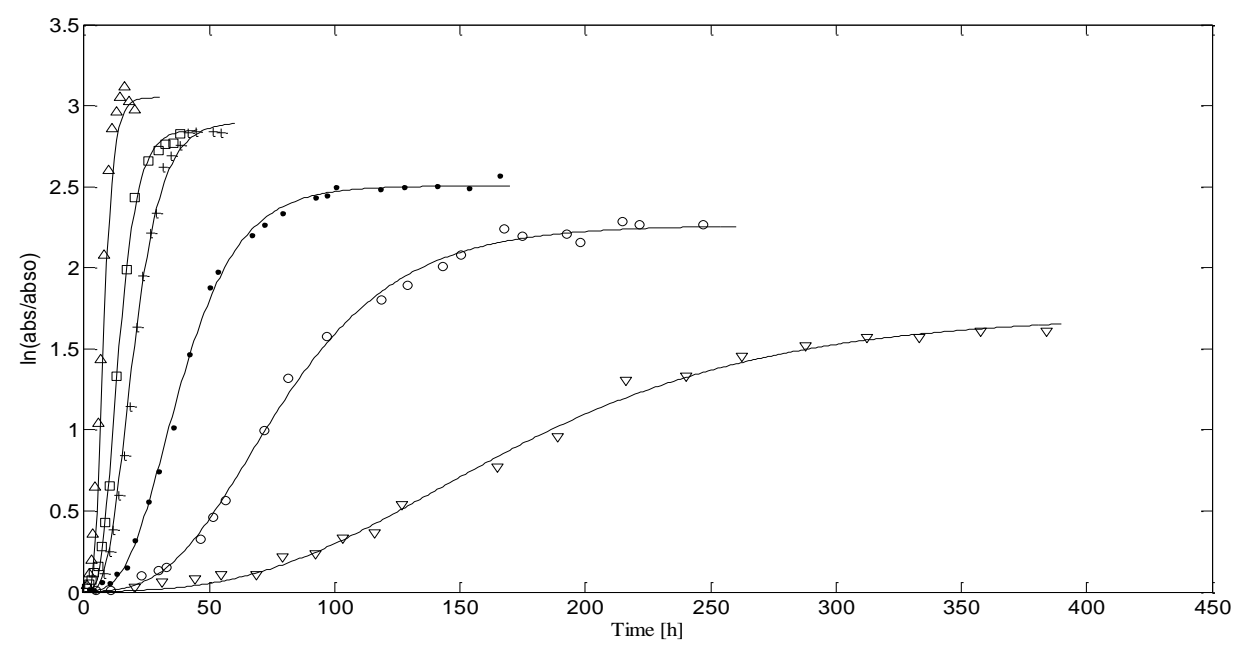

Figure 1. Example of $L$. viridescens growth curves in MRS broth at different temperatures. The lines represent the Gompertz model fit to experimental data (symbols). ( $\nabla) 4^{\circ} \mathrm{C},(\circ) 8^{\circ} \mathrm{C}$, (•) $12^{\circ} \mathrm{C},(+) 16^{\circ} \mathrm{C},(\square) 20^{\circ} \mathrm{C}$ and $(\Delta) 30^{\circ} \mathrm{C}$.

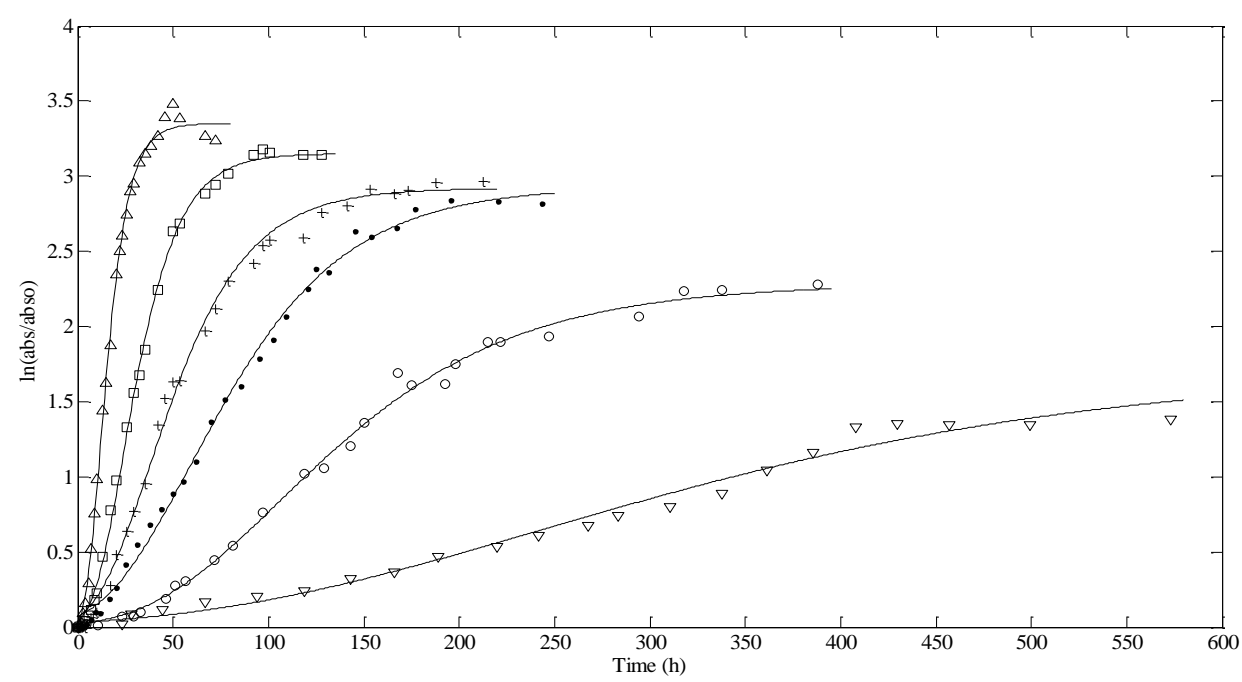

Figure 2. Example of $L$. sakei growth curves in MRS broth at different temperatures. The lines represent the Gompertz model fit to experimental data (symbols). ( $\nabla) 4^{\circ} \mathrm{C},(\circ) 8^{\circ} \mathrm{C},(\bullet)$ $12^{\circ} \mathrm{C},(+) 16^{\circ} \mathrm{C},(\square) 20^{\circ} \mathrm{C}$ and $(\Delta) 30^{\circ} \mathrm{C}$.

In real storage and commercialization of foodstuffs, it is known that temperature fluctuations can occur. The results showed that small increases in temperature (variation of 
$4^{\circ} \mathrm{C}$ ) interfered in all growth parameters. This way, it emphasizes the importance of controlling the chill chain, especially for refrigerated meat products that have a relatively short shelf-life, compared with other food products.

\section{CONCLUSIONS}

The primary model that showed the best fit to growth curves of $L$. viridescens and $L$. sakei at temperatures ranging from $4^{\circ} \mathrm{C}$ to $30^{\circ} \mathrm{C}$ was the Gompertz model. It is possible to conclude that the growth of LAB is strongly influenced by storage temperature, even under refrigeration conditions.

The shelf-life of a food product can be drastically reduced by temperature fluctuations and by temperature abuse, i.e., use of storage temperatures above the recommended for a given foodstuff. Although the experiments were developed in culture media, these datas could be helpful in the food industry, allowing for a better understanding of the behavior of the strains in meat products.

\section{REFERENCES}

Baranyi, J.; Roberts, T.A. 1994. A dynamic approach to predicting bacterial growth in food. Int. J. Food Microbiol. 23, 277-294.

Brul, S.; Mensonides, F.I.C.; Hellingwerf, K.J.; Mattos, M.J.T. 2008. Microbial systems biology: new frontiers open to predictive microbiology. Int. J. Food Microbiol. 128, 1621.

Buchanan, R.L.; Whiting, R.C.; Damert, W.C. 1997. When is simple good enough: A comparison of the Gompertz, Baranyi, and three-phase linear models for fitting bacterial growth curves. Food Microbiol. 14, 313-326.

Corradini, M.G.; Peleg, M. 2005. Estimating non-isothermal bacterial growth in foods from isothermal experiments data. J. Appl. Microbiol. 99, 187-200.

Erkmen, O.; Alben, E. 2002. Mathematical modeling of citric acid production and biomass formation by Aspergillus niger in undersized semolina. J. Food Eng. 52, 161-166.

Hugas, M. 1998. Bacteriocinogenic lactic bacteria for the biopreservation of meat and meat products. Meat Sci. 49, 139-150.

Nakashima, S.M.K.; André, C.D.S.; Franco, B.D.G.M. 2000. Revisão: Aspectos Básicos da Microbiologia Preditiva. Braz. J. Food Tech. 3, 41-51.

Nychas, G.J.E.; Skandamis, P.N.; Tassou, C.C.; Koutsoumanis, K.P. 2008. Meat spoilage during distribution. Meat Sci. 78, 77-89.

Pal, A.; Labuza, T.P.; Diez-Gonzalez, F. 2008. Comparison of primary predictive models to study the growth of Listeria monocytogenes at low temperature in liquid cultures and selection of fastest growing ribotypes in meat and turkey product slurries. Food Microbiol. 25, 460-470.

Ross, T. 1996. Indices for performance evaluation of predictive models in food microbiology. J. Appl. Bacteriol. 81, 501-508. 
Samelis, J.; Kakouri, A.; Rementzis, J. 2000. Selective effect of the product type and the packaging conditions on the species of lactic acid bacteria dominating the spoilage microbial association of cooked meats at $4^{\circ} \mathrm{C}$. Food Microbiol. 17, 329-340.

Slongo, A.P.; Rosenthal. A.; Camargo, L.M.Q.; Deliza, R., Mathias S.P.; Aragão, G.M.F. 2009. Modeling the growth of lactic acid bacteria in sliced ham processed by high hydrostatic pressure. LWT-Food Sci.Tech. 42, 303-306.

Sutherland, J.P.; Bayliss, A.J.; Roberts, T.A. 1994. Predictive modeling of growth of Staphylococcus aureus: the effects of temperature, $\mathrm{pH}$ and sodium chloride. Int. J. Food Microbiol. 21(3), 217-236.

Whiting, R.C. 1995. Microbial modelling in foods. Critical Rev. Food Sci. Nut. 35, 467-494.

Zwietering, M.H.; Jongeburger, I.; Rombouts, F.M.; Riet, K.V. 1990. Modeling of bacterial growth curve. Appl. Environ. Microbiol. 56, 1875-1881. 